\title{
Strategi Marketing Public Relations Dalam Meningkatkan Jumlah Pelanggan di PT. Bach Multi Global
}

\author{
Evita, Yugih Setyanto \\ Evita.915150022@stu.untar.ac.id,yugihs@fikom.untar.ac.id
}

Fakultas Ilmu Komunikasi Universitas Tarumanagara

\begin{abstract}
PT. Bach Multi Global is a company engaged in the sale, maintenance and repair of generator sets for telecommunications companies in Indonesia such as Telkomsel, XL, and Indosat. The generator sets sold are used for the tower base transceiver station (BTS) in the telecommunications company. Over time, the sale of generator sets to BTS began to decline. To be able to survive PT. BMG needs to increase the number of customers to other sectors such as retail, banking, construction. The purpose of this study is to determine the strategy of marketing public relations, public relations activities and how to increase the number of customers at PT. Bach Multi Global (BMG). The study used a qualitative descriptive method through data obtained by interviewing the company, namely the CEO, marketing public relations and also the customers of the company. The results of this study indicate that PT Multi Multi Global has implemented a marketing public relations strategy, namely its activities are to offer after-sales services to customers, advertising promotions, and sales calls to offices.
\end{abstract}

Keywords: Marketing Strategy, Public Relations, Public Relations Marketing

\begin{abstract}
Abstrak
PT. Bach Multi Global adalah perusahaan yang bergerak di bidang penjualan, pemeliharaan, dan perbaikan generator set untuk perusahaan telekomunikasi di Indonesia seperti Telkomsel, XL, dan Indosat. Generator set yang dijual digunakan untuk tower base transceiver station (BTS) pada perusahaan telekomunikasi tersebut. Seiring berjalannya waktu, Penjualan genset pada BTS mulai menurun. Untuk dapat bertahan PT. BMG perlu meningkatkan jumlah pelanggan ke sektor lain seperti, ritel, perbankan, konstruksi. Tujuan dari penelitian ini untuk mengetahui strategi marketing public relations, aktivitas public relations serta bagaimana cara meningkatkan jumlah pelanggan di PT. Bach Multi Global (BMG) . Penelitian menggunakan metode deskriptif kualitatif melalui data yang diperoleh dengan wawancara pihak perusahaan yaitu $C E O$ lalu, marketing public relations dan juga pelanggan-pelanggan dari perusahaan. Hasil penelitian ini menunjukkan bahwa PT.Bach Multi Global telah menerapkan strategi marketing public relations yaitu kegiatan nya adalah menawarkan layanan after sales kepada customer, promosi iklan, dan sales call ke kantorkantor.
\end{abstract}

Kata kunci : Strategi Marketing, Public Relations, Marketing Public Relations

\section{Pendahuluan}

Berbicara mengenai perusahaan maka tidak akan lepas dari urusan usaha. Perusahaan merupakan suatu organisasi yang mempunyai tujuan dalam menjalankan usahanya. Banyak berbagai macam bisnis yang sudah tersebar di Indonesia, untuk mengembangkan usahanya diterapkan berbagai macam cara. Persaingan bisnis yang kompetitif semakin hari semakin sulit ini menyebabkan setiap perusahaan akan memberikan pelayanan, fasilitas dan produk yang terbaik dari perusahaan mereka. 
Pemasaran merupakan salah satu usaha untuk memperkenalkan produk. Penerapan pemasaran yang dilakukan harus dengan pengetahuan dalam konsep dan prinsip pemasaran yang tepat. Dalam penelitian ini, penulis memilih perusahaan kontraktor telekomunikasi, dimana telekomunikasi adalah kebutuhan penting bagi orang Indonesia. Untuk menghubungkan lebih dari 260 juta orang yang tersebar di seluruh kepulauan yang luas ini telah menjadi tantangan yang nyata. Layanan selular khususnya, telah menonjol sebagai solusi. Operator ditantang untuk memberikan tidak hanya harga yang kompetitif, tetapi juga layanan berkualitas dan cakupan luas.

PT. Bach Multi Global (BMG) didirikan pada September 2006, bekerja sama dengan operator telekomunikasi membangun Menara Base Trannsceiver Station (BTS) untuk memfasilitasi komunikasi nirkabel antara pengguna di area yang jauh dari jaringan. Sebagai peyedia solusi telekomunikasi ujung ke ujung dalam instalasi, penyewaan dan pemeliharaan untuk BTS di berbagai wilayah Indonesia. PT. BMG meyediakan beberapa produk yaitu : Generator Genset, Heavy range, Rental, telcom contractor, power solution provider, sitac \& CME contractor, dengan fokus pemasangan dan perawatan sarana pendukung industri telekomunikasi besar di Indonesia seperti Telkonsel, XL, dan Indosat. Generator set yang dijual digunakan untuk tower base transceiver station (BTS) pada perusahaan telekomunikasi tersebut. Seiring berjalannya waktu, Penjualan genset pada BTS mulai menurun. Untuk dapat bertahan, maka PT. BMG perlu meningkatkan jumlah pelanggan ke sektor lain seperti, ritel, perbankan, konstruksi.

Marketing Public Relations (MPR) adalah sebuah proses perencanaan dan pengevaluasian program yang merangsang pembelian dan kepuasan pelanggan melalui informasi yang dapat dipercaya dan melalui kesan-kesan yang menghubungkan perusahaan dan produknya sesuai keinginan dan kepentingan para konsumen (Ruslan, 2002: 253)

Seorang $P R$ dituntut untuk dapat memperluas peranan nya dalam bidang pemasaran produk dan jasa, dimana strategi komunikasi diharapkan mampu menjaring konsumen atau pelanggan baru. Dalam pelaksanaannya, biasanya divisi $P R$ dan marketing bersinergi dengan merancang perencanaan, dan melalakukan evaluasi program-program marketing yang telah dijalankan. Kemudian divisi $P R$ dan marketing menyimpulkan sebuah program yang akan dijalankan untuk mendorong minat beli serta meningkatkan kepuasan pelanggan. Dalam hal ini, divisi $P R$ harus menyampaikan informasi dan kesan yang meyakinkan bahwa produk atau jasa yang ditawarkan sesuai dengan kebutuhan, keinginan, dan minat konsumen. Saat ini, ide-ide pemasaran dan penyampaian komunikasi memang memegang peranan yang penting. Dengan semakin pandai konsumen menyerap informasi dapat dengan mudah di akses, menjadikan fungsi $P R$ dalam hal pemasaran sangat diutamakan guna menjaring konsumen sebanyak-banyaknya. Dengan demikian, penulis tertarik untuk meneliti mengetahui bagaimana strategi marketing public relations yang dilakukan dalam PT. BMG untuk meningkatkan jumlah pelanggan.

\section{Metode Penelitian}

Menurut David William (2009:5) dalam Lexy J. Moleong mendefinisikan penelitian kualitatif adalah pengumpulan data pada suatu latar alamiah, dengan menggunakan metode alamiah, dan dilakukan oleh peneliti yang tertarik secara alamiah. Penulis buku penelitian kualitatif lainnya menurut Denzin dan Lincoln (2009) dalam Lexy J. Moleong menyatakan bahwa penelitian kualitatif adalah 
penelitian yang menggunakan latar alamiah, dengan maksud menafsirkan fenomena yang terjadi dan dilakukan dengan jalan melibatkan berbagai metode yang ada. Menurut Jane Richie (2009:6) dalam Lexy J. Moleong, penelitian kualitatif adalah upaya untuk menyajikan dunia sosial dan perspektif-nya di dalam dunia, dari segi konsep, perilaku, persepsi, dan persoalan tentang manusia yang diteliti.

Dari pernyataan di atas dapat disimpulkan bahwa penelitian kualitatif adalah penelitian yang bermaksud untuk memahami riset dengan fokus terhadap latar belakang masalah yang ada.

Dalam penelitian ini digunakan pendekatan studi kasus sebagai bagian dari penelitian kualitatif. Penelitian studi kasus memusatkan diri secara insentif pada suatu objek tertentu yang mempelajarinya sebagai suatu kasus. Penelitian studi kasus dimaksudkan untuk meneliti secara mendalam, tentang latar belakang masalah dan posisi suatu gejala yang berlangsung pada kehidupan nyata. Subjek penelitian dapat berupa individu, kelompok, intuisi atau masyarakat. Penelitian studi kasus merupakan studi mendalam mengenai unit sosial tertentu dan hasil penelitian tersbut dalam memberikan gambaran luas, serta mendalam mengenai unit sosial tertentu. Sementara itu, menurut Danim (2014: 112) dalam Imam Gunawan berpendapat bahwa subjek yang diteliti relative terbatas, namun variable-variable dan fokus yang diteliti sangat luas dimensinya. Menurut Stake (2014: 114) dalam Imam Gunawan mengemukakan case study is not a methodological choice but a choice of what to be studied. Pada penelitian kualitatif, terdapat objek penelitian yang harus dipandang secara khusus, agar hasil penelitiannya mampu menggali semuanya secara terperinci dan menyeluruh dibalik fakta.

\section{Hasil Temuan dan Diskusi}

Pada bab ini dalam bagian analisis, penulis akan melakukan analisis data dari hasil penelitian yang telah di dapatkan dan akan memaparkan hasil wawancara dari narasumber serta memberikan beberapa pandangan penulis berdasarkan jawaban dari narasumber yang telah penulis wawancarai, pada sub bab ini penulis juga akan memaparkan mengenai pandangan narasumber terhadap kegiatan marketing Public Relations dalam mengembangkan PT. Bach Multi Global sehingga pelanggan makin meningkat.

\section{a. Strategi Push}

Merupakan upaya untuk merangsang pembelian dalam hal memberikan nilai tambah (added value) atau kepuasan bagi pelanggan (satisfied customer) yang telah menggunakan produk perusahaan.

Strategi ini dijalankan oleh PT. Bach Multi Global dengan menawarkan layanan purna jual (aftersales service) yang baik agar pelanggan yang sudah ingin melakukan pembelian merasa yakin dan percaya dengan perusahaan. 


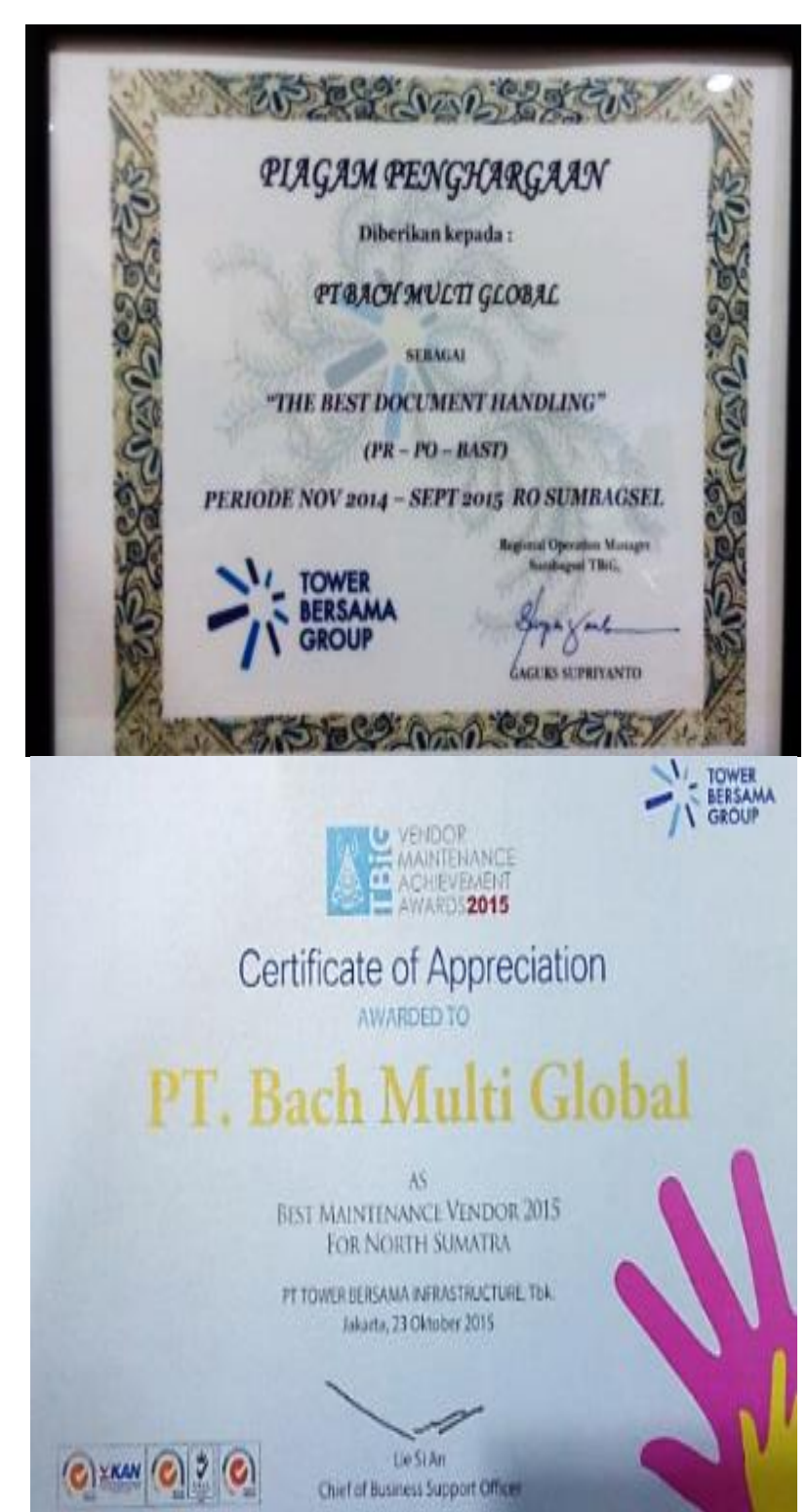

Sertifikat Penghargaan PT. Bach Multi Global

Selain memberikan nilai tambah dari produk yang ditawarkan berupa layanan purna jual yang baik, PT. Bach Multi Global juga memberikan bukti testimoni serta penghargaan yang telah di dapatkan oleh perusahaan dalam membantu mendapatkan kepercayaan dari pelanggan.

\section{b. Stategi Pull}

Pada strategi ini, adalah kegiatan mempromosikan dan menjual merek atau produknya. Perangkat dari pull strategi ini biasanya adalah media massa, media khusus, event sponsorship, program audiens khusus dan lain sebagainya.

Sebagai salah satu usaha dalam menarik perhatian publik maka PT. Bach Multi Global memilih untuk melakukan iklan di media cetak seperti di koran Kompas, selain itu untuk menjangkau lebih banyak audience maka PT. Bach Multi Global juga melakukan advertising online seperti menggunakan layanan Google Ads yang ditujukan ke website $w w w$.bachmultiglobal.co.id 
Evita, Yugih Setyanto: Strategi Marketing Public Relations Dalam Meningkatkan Jumlah Pelanggan di PT. Bach Multi Global

Usaha lain yang dilakukan adalah dengan mengirimkan karangan bunga kepada customer. Selain dapat memberikan nilai lebih di mata customer, karangan bunga yang diberikan juga akan membantu dalam usaha menarik perhatian publik.

\section{c. Strategi Pass}

Strategi membujuk dengan kegiatan partisipasi masyarakat untuk pendukung strategi push dan pull, Seperti bencana gempa bumi yang baru terjadi menimpa Kota Palu pada bulan Oktober 2018 lalu, PT. Bach Multi Global juga turut membantu dalam menyediakan unit genset yang digunakan untuk arus listrik menara.

BTS (base transceiver station) sehingga sinyal telekomunikasi seluler di daerah pasca gempa tidak terganggu dan dapat mempermudah aksi evakuasi korban gempa.

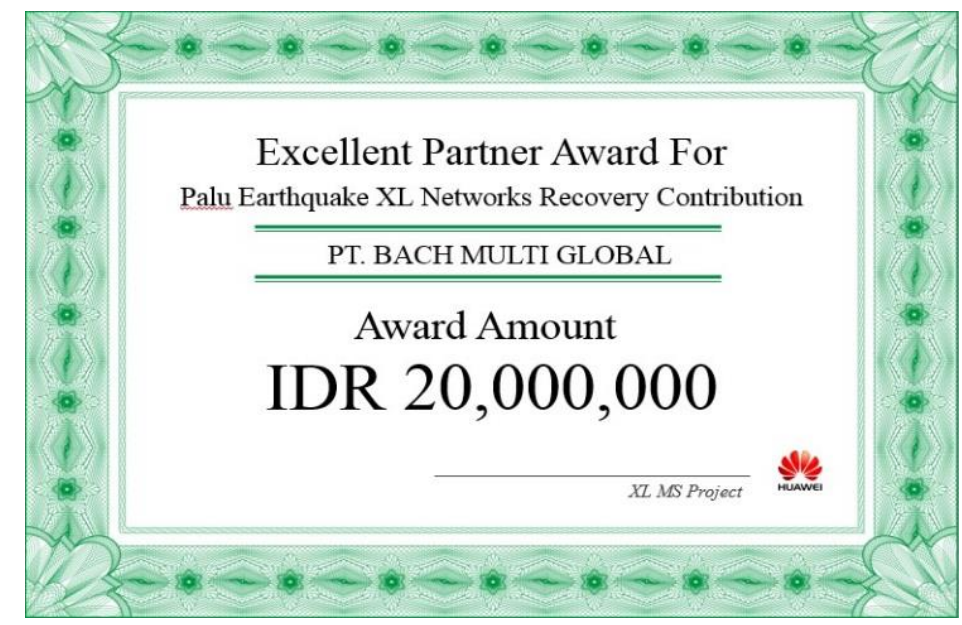

Piagam Penghargaan Kontribusi Gempa Palu

Pada bab sebelumnya, penulis telah memaparkan dengan menggunakan Push Strategy, Pull Strategy dan Pass Strategy dapat mempengaruhi pelanggan dengan melakukan berbagai kegiatan marketing Public Relations yang dilakukan divisi marketing PT. Bach Multi Global sehingga dapat mencari keuntungan serta meningkatkan penjualan dan juga meningkatkan jumlah pelanggan. PT. Bach Multi Global mempunyai pemikiran bahwa pentingnya untuk mengupayakan secara maksimal pelayanan dan menjalankan komunikasi yang baik untuk menjalin kerja sama. Dari pemikiran ini, PT. Bach Multi Global selalu dekat dengan para anggotanya dan pelanggannya dengan melakukan berbagai kegiatan marketing public relations.

Penulis telah melakukan wawancara dengan pihak internal PT. Bach Multi Global dalam mengembangkan data yaitu : CEO dan marketing PR. Pada tahap pertama penulis melalukan wawancara dengan marketing PR PT. Bach Multi Global , bapak William (07 November 2018) yang kedua dengan CEO perusahaan yaitu bapak Budi kurniawan (16 November 2018) dan bahwa kegiatan marketing public relations yang dilakukan devisi marketing PT. Bach Multi Global dalam meningkatkan jumlah pelanggan adalah sebagai berikut :

"Kegiatan Marketing Public Relations yang kami lakukan adalah mengupayakan maksimal dalam hal nilai tambah yang ada di BMG kepada customer kami, Meningkatkan kualitas produk/jasa dimana barang bagus tapi harga kompetitive sebagai basic dalam ilmu pemasaran,tetap harus menjadi dasar pemikiran sehingga bagi kami perlu di bangun 
komunikasi,trust each others di mana BMG merupakan mitra yang bisa memberikan solusi dalam segala apapun pekerjaan yang di berikan kepada kami dan promosi di media cetak maupun di pameran dan menggunakan media digital”.

Pernyataan CEO PT. Bach Multi Global (Budi Kurniawan) tersebut sejalan juga dengan pendapat William selaku Marketing PR PT. Bach Multi Global, yang mengatakan bahwa

"Kegiatan Marketing Public Relations yang dilakukan oleh PT. Bach Multi Global adalah memberikan nilai lebih di mata customer seperti harga yang menarik, after sales yang terpercaya, dan tentunya komunikasi yang baik dan reputasi integritas perusahaan yang dimana harus selalu dijaga, seperti tidak melakukan kecurangan pada saat proses supply genset dan juga tidak melakukan KKN dalam kerja sama antar perusahaan.”

Melalui kedua pandangan wawancara dari pihak internal, penulis mengambil kesimpulan bahwa PT. Bach Multi Global berpendapat bahwa setiap Marketing Public Relations yang dijalankan PT. Bach Multi Global sangat penting bagi perusahaan, karena pada dasarnya PT. Bach Multi Global merupakan mitra yang bisa memberikan solusi dan mengutamakan kepuasan pelanggan. Selain itu, dengan menjalankan kegiatan Marketing Public Relations serta dibantu dengan strategi push dan strategi pull sebagai alat pemancing dan perangsang. Ini merupakan salah satu cara bagi perusahaan untuk mendekatkan diri kepada pelanggan dan meningkatkan jumlah pelanggan.

Seperti yang dikatakan Thomas L. Harris dalm bukunya berjudul The Marketer's Guide to Public Relations adalah "Merkerting Public Relations is the process of planning and evaluating programs, that encourage purchase and customer through credible communication of information and impression that identify companies and their productswith the needs, concern of customer" Artinya, sebuah proses perencanaan dan pengevaluasian program yang merangsang pembelian dan kepuasan pelanggan melalui informasi yang dapat dipercaya dan menghubungkan perusahaan dengan produknya sesuai keinginan dan kepentingan para konsumen (Ruslan, 2002). Hal tersebut dilakukan melalui pengkomunikasian informasi yang kredibel dan dapat menumbuhkan rasa kepuasaan bagi pelanggan sehingga dapat meningkatkan jumlah pelangan. Akan tetapi, dari setiap kegiatan tersebut dan hasil wawancara dapat disimpulkan bahwa melalui layanan after sales service yang baik pelanggan merasa puas dan yakin kepada perusahaan.

Beberapa ahli mengemukakan pengertian after-sales-service seperti diuraikan dengan definisi berikut ini:

Menurut Patton (2002,) menyatakan after sales service adalah "a product support that can keep the product work properly for along time". Suatu layanan pendukung produk yang bertujuan untuk membuat suatu produk dapat bekerja dengan wajar untuk jangka waktu yang lama.

Menurut Hindle \& Thomas (2004) mendefinisikan after sales service sebagai "a service that provided by the company to their costumers, after the customer purchasing their product". Suatu layanan yang disediakan oleh produsen kepada seorang konsumen, setelah konsumen tersebut melalukan pembelian pada produsen tersebut. 
Evita, Yugih Setyanto: Strategi Marketing Public Relations Dalam Meningkatkan Jumlah Pelanggan di PT. Bach Multi Global

Berdasarkan definisi-definisi di atas dapat disimpulkan after sales service adalah bentuk layanan sebagai hal nilai tambah kepada kostumer yang telah menggunakan produknya.

\section{Simpulan}

Strategi Marketing Public Relations yang dilakukan PT. Bach Multi Global adalah Strategi Push, Strategi Pull, dan Strategi Pass yang dapat merangsang pembelian pelanggan dengan melakukan berbagai kegiatan marketing Public Relations yang dilakukan PT. Bach Multi Global dapat mencari keuntungan serta meningkatkan penjualan dan juga meningkatkan jumlah pelanggan.

Kegiatan Marketing Public Relations yang dilakukan adalah mengupayakan maksimal dalam hal nilai tambah yang ada di BMG kepada customer, Meningkatkan kualitas produk/jasa dimana barang bagus tapi harga kompetitif dan promosi di media cetak maupun media digital.

\section{Ucapan Terimah Kasih}

Ucapan Terimah kasih penulis berikan kepada narasumber yang bersedia untuk memberikan informasi kepada peneliti selama proses pengumpulan data dalam penelitian ini. Peneliti juga ingin megucapkan terimah kasih kepada

\section{Daftar Pustaka}

Arikunto, Suharsimi. (2002). Prosedur Penelitian Suatu Pendekatan Praktik. Jakarta: Rineka Cipta.

Cutlip, Scott M. (2007). Effective Public Relations Edisi 9. Jakarta : Kencana.

Effendy, Onong Uchjana. (2003). Ilmu Teori dan Filsafat Komunikasi. Bandung dosen pembimbing serta Fakultas Ilmu Komunikasi Universitas Tarumanagara.

Gunawan, Imam. (2014). Metode Penelitian Kualitatif : Teori dan Praktik. Jakarta:Bumi Aksara.

Hindle, Tim dan Thomas, Michael. (2004). Seri Intisari Manajemen Pemasaran terjemahan Damiano Q. Roosmin. Jakarta : Gramedia.

Jefkins, Frank. (2003). Public Relations Edisi kelima, Jakarta: PT Gelora Aksara Pratama.

Jefkins, Frank. (2004). Public Relations. Jakarta : Erlangga.

Moleong, Lexy. J. (2006). Metode Penelitian Kualitatif. Bandung: PT Remaja Rosdakarya.

Moleong, Lexy. J. (2009). Metode Penelitian Kualitatif. Bandung: PT Remaja Rosdakarya.

Moleong, Lexy. J. (2010). Metode Penelitian Kualitatif. Bandung: PT Remaja Rosdakarya.

Patton, M. Q. (2002). Qualitative Research \& Evaluation Methods. Third Edition. California: Sage Publications.

Ruslan, Rosadi. (2002). Manajemen Public Relations dan Media Komunikasi: Konsepsi dan Aplikasi, Jakarta: PT Raja Grafindo Persada.

Ruslan, Rosadi. (2008). Manajemen Public Relations dan Media Komunikasi. Jakarta : Rajawali Pers. 
Ruslan, Rosadi. (2010). Manajemen Public Relations dan Media Komunikasi, Jakarta : Rajawali Pers.

Sugiyono,(2009). Metode Penelitian Kuantitatif Kualitatif dan R\&D. Bandung : Alfabeta.

Sugiyono, (2010). Metode Penelitian Kuantitatif Kualitatif dan R\&D. Bandung: Alfabeta.

West, Richard, Lynn H. Turner. (2008). Pengantar Teori Komunikasi Analisis dan Aplikasi Edisi 3 Buku 1. Terjemahan Maria Natalia.

West, Richard, Lynn H. Turner. (2010). Pengantar Teori Komunikasi Analisis dan Aplikasi Edisi 3 Buku 2. Jakarta: Salemba Humanika. 